\title{
Application of PBL Mode in a Resident-Focused Perioperative Transesophageal Echocardiography Training Program: A Perspective of MOOC Environment
}

This article was published in the following Dove Press journal:

Advances in Medical Education and Practice

\author{
Lini Dong' \\ Lin Yang ${ }^{2,3}$ \\ Zhijian $\mathrm{Li}^{2,3}$ \\ Xin Wang ${ }^{2,3}$ \\ 'Department of Geriatrics, The Second \\ Xiangya Hospital of Central South \\ University, Changsha, Hunan, China; \\ ${ }^{2}$ Department of Anesthesiology, The \\ Second Xiangya Hospital of Central \\ South University, Changsha, Hunan, \\ China; ${ }^{3}$ Anesthesia Medical Research \\ Center of Central South University, \\ Changsha, Hunan, China
}

Background: Massive open online courses (MOOCs) is a new teaching technology based on a network platform, which can provide more students with the possibility of systematic and repeated learning. Due to the complexity of transesophageal echocardiography (TEE), the wide range of knowledge involved, and many knowledge points being difficult to understand, it is difficult to meet the teaching needs of this content with the traditional teaching mode. This study aimed to discuss the application of lecture based learning (LBL) and problem based learning $(\mathrm{PBL})$ in the training of perioperative TEE in the context of MOOCs.

Methods: Sixty residents were randomly divided into two groups to participate in a 5-day perioperative TEE training program. The web-based PBL mode was used in the observation group and the LBL mode was used in the control group, with 30 residents in each group. The teaching effect of the web-based PBL mode was compared with the LBL mode by basic theory test, practice examination, image interpretation and questionnaire.

Results: The image interpretation score and the total test score were higher in the observation group than in the control group with statistically significant differences $(P<0.001)$. The results of the questionnaire show that the residents were more satisfied with the web-based PBL mode than the LBL mode $(P<0.001)$.

Conclusion: The web-based PBL method has obvious advantages over the LBL mode in the training of perioperative TEE.

Keywords: residents training, TEE, MOOC, PBL, LBL
Correspondence: Xin Wang Email wangxin6688@csu.edu.cn

\section{Introduction}

With the development of perioperative medical science, ultrasound technology has become a desirable skill for anesthesiologists to implement anesthesia operation and real-time diagnosis to achieve precise medical treatment. TEE technology has been widely used in cardiovascular surgery in recent years. It can not only be used for preoperative diagnosis, but also can evaluate the related indexes of the valve and dynamic monitoring of the cardiac function during the perioperative period. It is a vital perioperative technique of cardiovascular surgery. ${ }^{1}$ In the United States and Europe, perioperative TEE was vigorously promoted, and it has gradually been included in the standardized training of residents. ${ }^{2,3}$ However, the training of residents for perioperative TEE is still weak in China. There are several continuing medical education 
programs held by some qualified medical institutions that address the educational needs of perioperative applications of TEE every year. Participation requires significant commitment of resources (e.g., time and money) from the participating residents. In addition to being specialty focused, these programs often do not evaluate the teaching effect after training. Meanwhile, due to the complexity of TEE, the wide range of knowledge involved, and many knowledge points being difficult to understand, it is difficult to meet the teaching needs of this content with the traditional teaching mode. The current theoretical teaching, simulation teaching, and short-term training still make it difficult for learners to fully master this skill. ${ }^{4}$ Also, there are no available mechanisms for recognition or demonstration of proficiency or expertise. Therefore, the current education model for training in perioperative TEE does not address comprehensively the requirement of broad knowledge and skill sets required for proficiency of the practicing anesthesiologists.

Massive open online courses (MOOCs) is a new teaching technology based on a network platform, which challenges the traditional education model. MOOCs can reach a large number of learners, which has a positive and long-term impact on open education. The MOOC network platform can create online learning opportunities for students, and provide more students with the possibility of systematic and repeated learning. ${ }^{5}$ The emergence of problem-based learning methods challenges the traditional education model. On the basis of the MOOC platform, combined PBL (problem based learning) with traditional LBL (lecture based learning) is a brand new teaching concept, which is quite different from the traditional teaching methods. It guides students to learn knowledge and skills based on problems, so that the learners can better understand and master knowledge points.

\section{Methods}

The study on TEE education was conducted in November 2019. It received institutional review board approval for exempt status by the Committee on Clinical Investigations at The Second Xiangya Hospital. Postgraduate year-2/3 anesthesia residents at our institution were invited to participate in the course. These residents were licensed, and had at least 1 year of experience in cardiovascular anesthesia. Sixty residents were invited to participate in a multimodal perioperative TEE course. Before the training, these residents had taken a theoretical examination to determine their baseline levels. Then the residents were randomly divided into two groups: the PBL mode was used in the observation group and the LBL mode was used in the control group, with 30 residents in each group. The training course lasted for 5 days, and was divided into primary training and advanced training (Figure 1). The primary training included basic theoretical knowledge courses (14 classes, 30-60 minutes per class) and simulated human teaching (4 classes, 1 hour per class). Advanced training included clinical application courses of perioperative TEE (23 classes, 30-60 minutes each) and a clinical observation course (4 hours). In this course, residents were introduced to the general principles of TEE, equipment operation, and workflow understanding; comparison of normal anatomy and physiology to pathological findings and the differential diagnoses of such findings also were introduced.

LBL was a traditional teaching mode group, that is, after residents entered the perioperative TEE training class, they would be taught in the traditional mode (including all the contents of primary and advanced training contents). PBL was a problem-based teaching mode group, that is, after residents entered the perioperative TEE training class, in addition to the contents of the LBL mode, they were also provided with the network learning platform and the synchronization of the teaching courses. PBL mode was used to

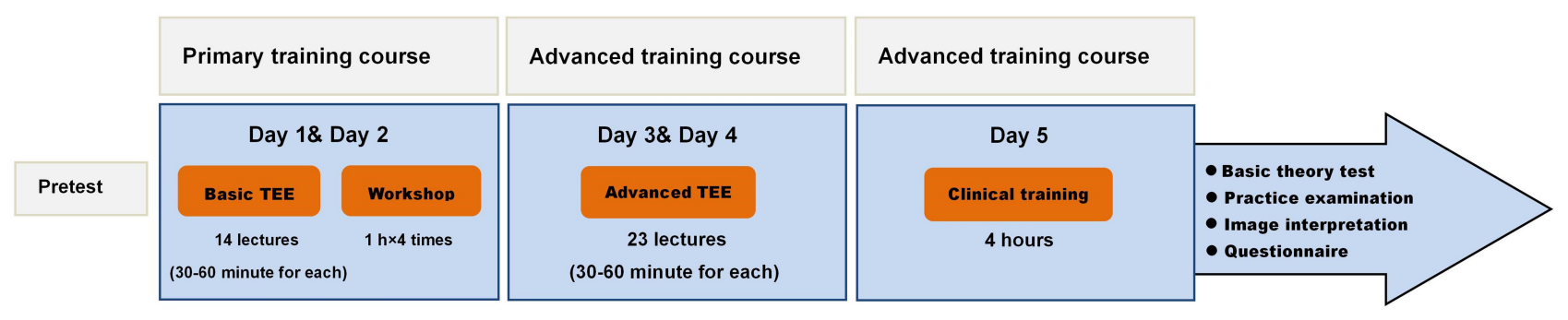

Figure I Residents' perioperative TEE training course. The course was the introduction of TEE for perioperative use via an instructional and evaluative program of didactic and hands-on components. In this course, the residents were introduced to the general principles of TEE, equipment operation, and workflow understanding; comparison of normal anatomy and physiology to pathological findings and the differential diagnoses of such findings also were introduced.

Abbreviation: TEE, transesophageal echocardiography. 
conduct on-site teaching, which provided timely answers and guidance for the problems encountered by residents in the learning process. Meanwhile, teachers with rich clinical and teaching experience were arranged to organize discussions, and residents were timely notified and organized to participate in the discussions.

\section{Online Component}

The content of the lectures were synchronized and available online at $<$ https://webcast.vyuan8.cn/vyuan/plugin. php?id=vyuan zhibo\&mod=viewpc\&identify $=5722150>$.

The course registration was free and open to anyone. After the completion of the learning content, the residents were assessed. The course arrangement and examination process are shown in Figure 1.

\section{Observation Index of Teaching Effect}

The results were based on a percentage system and were divided into three parts: (1) Basic theory test: the residents were given 16 multiple choice questions and one $\mathrm{Q}$

$\&$ A question (accounting for $30 \%$ of the total score); (2) Practice examination: residents were evaluated by use of simulators in the simulation teaching center to obtain the standard imaging views of the TEE and analyze cases of coronary heart disease or valvular disease (accounting for $30 \%$ of the total score); (3) Image interpretation: given 16 TEE images, residents were required to make the correct choice of normal cardiac structure or pathological features in the images (accounting for $40 \%$ of the total score). The basic requirements for the TEE training are shown in Table 1.

Focused on the investigation of learning enthusiasm, satisfaction with teaching methods, interest in the perioperative TEE learning and choice of ways to acquire

Table I Basic Requirements for the TEE Training

\begin{tabular}{|c|c|}
\hline $\begin{array}{l}\text { Training Program } \\
\text { Requirements }\end{array}$ & Basic Standard \\
\hline Professional course & At least 30 class hours \\
\hline $\begin{array}{l}\text { Guided operation and } \\
\text { interpretation }\end{array}$ & At least 10 cases of simulator \\
\hline $\begin{array}{l}\text { Guided image } \\
\text { interpretation }\end{array}$ & At least 10 cases of simulator \\
\hline $\begin{array}{l}\text { Perioperative } \\
\text { examination }\end{array}$ & $\begin{array}{l}\text { At least } 3 \text { cases (including at least one } \\
\text { patient with coronary heart disease and } \\
\text { one patient with valvular disease } \\
\text { respectively, and complete the examination } \\
\text { report) }\end{array}$ \\
\hline
\end{tabular}

Table 2 Comparison of Academic Performance Between the Two Groups (Score, $x \pm s$ )

\begin{tabular}{|l|l|l|l|l|}
\hline Examination & $\begin{array}{l}\text { Observation } \\
\text { Group } \\
(\mathbf{n = 3 0})\end{array}$ & $\begin{array}{l}\text { Control } \\
\text { Group } \\
(\mathbf{n}=30)\end{array}$ & $t$ value & $P$ value \\
\hline Pretest & $62.87 \pm 3.03$ & $63.97 \pm 3.34$ & 1.338 & 0.186 \\
\hline Basic theory & $81.63 \pm 1.81$ & $82.37 \pm 1.76$ & 1.640 & 0.106 \\
\hline $\begin{array}{l}\text { Practice } \\
\text { examination }\end{array}$ & $84.73 \pm 2.03$ & $85.13 \pm 1.01$ & 0.965 & 0.345 \\
\hline $\begin{array}{l}\text { Image } \\
\text { interpretation }\end{array}$ & $89.67 \pm 4.90$ & $83.33 \pm 4.61$ & 5.155 & $0.000^{*}$ \\
\hline Total score & $85.78 \pm 2.38$ & $83.58 \pm 1.82$ & 4.013 & $0.000^{*}$ \\
\hline
\end{tabular}

Notes: Group $t$-test, $d f=58, a=5 \%$, two-tailed test. $P$-values are rounded to 3 decimal places. * denotes $P<0.05$.

knowledge, the teaching effect was evaluated through a teaching and learning feedback questionnaire survey or wechat app communication group.

\section{Statistical Analysis}

SPSS 19.0 statistical software (SPSS Inc., Chicago, Illinois, USA) was used for all data. Measurement data were expressed as mean \pm standard deviation, and group $t$-test was used for the inter-group comparison. $\mathrm{P}<0.05$ was considered a statistically significant difference.

\section{Results}

\section{Comparison of Academic Performance}

All the 60 residents completed the training. The results of the two groups showed that there was no significant difference in the scores of basic theory and practice examination between the two groups, but the scores of the image interpretation and the total score of the observation group were higher than that of the control group, and the difference was statistically significant $(P<0.05)$ (Table 2$)$.

\section{Survey on the Satisfaction of Residents with Teaching}

Comparing the learning satisfaction of residents in the two groups with the teaching, we found that the overall satisfaction of the observation group was higher than that of the control group (Table 3).

\section{Discussion}

Ultrasound is non-radiative, and the ultrasound machine is flexible in operation, so ultrasound technology is 
Table 3 Survey of the Residents' Satisfaction with the Teaching (Score, $x \pm s$ )

\begin{tabular}{|l|l|l|l|}
\hline & $\mathbf{n}$ & Teaching Mode & Teaching Effect \\
\hline Observation group & 30 & $8.71 \pm 0.29$ & $8.69 \pm 0.25$ \\
\hline Control group & 30 & $7.48 \pm 0.36$ & $7.53 \pm 0.25$ \\
\hline$t$ value & & 14.444 & 17.997 \\
\hline$P$ value & & $0.000^{*}$ & $0.000^{*}$ \\
\hline
\end{tabular}

Notes: Group $t$-test, $\mathrm{df}=58, \mathrm{a}=5 \%$, two-tailed test. $P$-values are rounded to 3 decimal places. $*$ denotes $P<0.05$.

convenient to use in the perioperative period. With the demands of medical development and the ongoing renewal of the technology, ultrasound has gradually penetrated and applied in multidisciplinary fields including emergency medicine, intensive care, and anesthesia. ${ }^{3}$ Ultrasound plays an important role in perioperative medicine. It is one of the key technologies for accurate evaluation and decision-making of anesthesiologists. ${ }^{6}$ The application of ultrasound technology to implement anesthesia operation and real-time diagnosis so as to achieve accurate medical treatment has become a desirable skill for anesthesiologists. ${ }^{1,7}$ In the United States and Europe, perioperative TEE was vigorously promoted, and its development has become increasingly mature. About 10 years ago, ultrasound training was incorporated into postgraduate training for residents of emergency and critical care medicine in the United States and Canada. ${ }^{8,9}$ In the following years, several guidelines and expert recommendations in the United States strongly advocated the inclusion of TEE in the standardized resident training., In Europe, the training courses and qualifications of perioperative TEE are mainly organized by the European Association of Cardiothoracic Anesthesiologists and the European Association of Cardiovascular Imaging, and the training process is relatively strict. ${ }^{3}$ Perioperative TEE has been vigorously developed and become increasingly sophisticated over the years, but it is still the weakest link in China. In recent years, Chinese experts suggest that it is imperative for anesthesiologists to receive standardized perioperative TEE training. ${ }^{10}$

Ultrasonic examination is largely affected by the subjective judgment of the operator, and it can only be used to advantage by a skilled operator. In order to be fully competent in TEE and provide reliable evidence for clinical diagnosis and treatment, in addition to mastering the professional theoretical knowledge of TEE, it is necessary to establish systematic and standardized training through systematic theoretical learning, simulation training, and clinical practice to improve the quality and effectiveness of the learning. Ensuring that trainees achieve the necessary clinical mindset and judgment ability is a prerequisite to improve the quality of anesthesia management and guarantee the safety of the patients. ${ }^{10}$ Chinese scholars are also strongly promoting TEE training, but at present, it is mainly carried out in the form of simulation teaching and training classes, and it is not combined with the MOOC teaching mode through the network platform.

To strengthen the management of the training, we should not only improve our understanding from the perspective of ideology, but also innovate in terms of methods and means. Using advanced computer network technology and relying on the existing network environment, the teaching management network system is established to monitor the whole process in real time. It is an advanced means to ensure the quality of the training. The education mode under the environment of MOOC has become the inevitable trend of education reform and development. ${ }^{11}$ Network teaching provides a highly interactive virtual platform that breaks through the time and space limitations for TEE teaching. ${ }^{12}$ On this basis, the PBL method has changed the general mode of knowledge acquisition in medical education, stimulated the students' learning motivation with clinical problems, and guides the students to grasp the key points of learning. ${ }^{13}$ PBL mode is a problem-based, student-centered group discussion teaching mode. ${ }^{14}$ At present, PBL medical education has begun to take root and grow in many medical colleges in China. TEE is a comprehensive and practical subject, which is very suited to the PBL mode to help the learners better understand and master the knowledge points.

The results of this study showed that the observation group (PBL mode) had higher image interpretation and total score than the control group (LBL mode). The traditional LBL mode is mainly based on teachers' lectures. In LBL mode, the teaching content is easy to be programmed and the participation of the learners is often lower, which restricts the development of the learners' thinking. As a result, students often lack the comprehensive ability to analyze complex symptoms and signs. It is easy for the students to form directional thinking in clinical practice, so that misdiagnosis or missed diagnosis may occur in practical work. ${ }^{15}$ Many changes have taken place in medical education under the MOOC environment. The introduction of PBL into teaching is quite different from the 
traditional LBL mode. The comparison between PBL mode and LBL mode is like a comparison between active learning and passive learning. Therefore, it is reasonable for the learners in the PBL mode to understand and master knowledge better than in the LBL mode. ${ }^{16}$

\section{Conclusion}

The purpose of the perioperative TEE training is to enable anesthesiologists to master bedside ultrasound technology, solve practical problems, improve diagnostic efficiency, and optimize perioperative safety management. The training course was conducted four times between November 2016 and November 2019. In the operation of these fourtraining courses, we have organized many discussions on problems. The enthusiasm of the trainees for the training has been greatly mobilized. The application of web-based $\mathrm{PBL}$ in perioperative TEE training for the residents showed that the web-based PBL mode was more conducive to improving the quality of perioperative TEE training for the residents and more in line with the requirements of medical education under the current MOOC environment when compared with the traditional LBL mode. This mode of teaching was well received and praised by the residents. Of course, this teaching mode cannot replace the traditional LBL and clinical learning. The purpose of the learning platform is to assist teaching and to serve as a useful supplement to lecture-based teaching and clinical learning.

\section{Ethics Approval and Consent to Participate}

This study was considered exempt from requirements for formal ethical approval further to scrutiny using the Second Xiangya Hospital of Central South University Ethics Review Committee Level 1 Self-Audit checklist, which involved completion of the checklist in written form by the principal investigator. As this work was carried out in accordance with the Declaration of Helsinki, the anonymity of participants is guaranteed, and the informed consent of participants was obtained.

\section{Acknowledgments}

The author acknowledges the support of the Research project on education and teaching reform of Central South University (2019JY180) and Hunan Provincial Health Project (Xiangcai Society Index (2019) No. 74).

\section{Disclosure}

The authors report no conflicts of interest. The authors alone are responsible for the content and writing of the article.

\section{References}

1. Coker BJ, Zimmerman JM. Why anesthesiologists must incorporate focused cardiac ultrasound into daily practice. Anesth Analg. 2017;124(3):761-765. doi:10.1213/ANE.0000000000001854

2. Smith WB, Robinson AR, Janelle GM. Expanding role of perioperative transesophageal echocardiography in the general anesthesia practice and residency training in the USA. Curr Opin Anaesthesiol. 2015;28(1):95-100. doi:10.1097/ACO.0000000000000146

3. Mahmood F, Matyal R, Skubas N, et al. Perioperative ultrasound training in anesthesiology: a call to action. Anesth Analg. 2016;122 (6):1794-1804. doi:10.1213/ANE.0000000000001134

4. Nazarnia S, Subramaniam K. Role of simulation in perioperative echocardi- ography training: current evidence and future directions. Semin Cardiothorac Vasc Anesth. 2016;21(1):81-94. doi:10.1177/ 1089253216655874

5. Pickering JD, Henningsohn L, Deruiter MC, et al. Twelve tips for developing and delivering a massive open online course in medical education. Med Teach. 2017;39(7):1-6. doi:10.1080/ 0142159X.2017.1322189

6. Fagley RE, Haney MF, Beraud AS, et al. Critical care basic ultrasound learning goals for American anesthesiology critical care trainees: recommendations from an expert group. Anesth Analg. 2017;120(5):1041-1053. doi:10.1213/ANE.0000000000000652

7. Ramsingh D, Rinehart J, Kain Z, et al. Impact assessment of perioperative point-of-care ultrasound training on anesthesiology residents. Anesthesiology. 2015;123(3):670-682. doi:10.1097/ ALN.0000000000000776

8. Akhtar S, Theodoro D, Gaspari R, et al. Resident training in emergency ultrasound: consensus recommendations from the 2008 council of emergency medicine residency directors conference. Acad Emerg Med. 2009;2(16):S32-S36. doi:10.1111/j.1553-2712.2009.00589.x

9. Mazraeshahi RM, Farmer JC, Porembka DT. A suggested curriculum in echocardiography for critical care physicians. Crit Care Med. 2007;35 (8):S431-S433. doi:10.1097/01.CCM.0000270280.65365.AA

10. Sheng W, Wang E, Hai YU, et al. It is imperative for anesthesiologists to receive standardized training of perioperative transesophageal echocardiography. Periop Saf Qual Assur. 2017;1(3):117-120.

11. Salinitri FD, Lobkovich AM, Crabtree BL, et al. Reliability and validity of a checklist to evaluate student performance in a problem-based learning group. Am J Pharm Educ. 2019;83(8):6963. doi:10.5688/ajpe6963

12. Tieman J, Miller-Lewis L, Rawlings D, et al. The contribution of a MOOC to community discussions around death and dying. $B M C$ Palliat Care. 2018;17(1):1-16. doi:10.1186/s12904-018-0287-3

13. Frambach JM, Talaat W, Wasenitz S, et al. The case for plural PBL: an analysis of dominant and marginalized perspectives in the globalization of problem-based learning. Adv Health Sci Educ. 2019;24 (5):931-942. doi:10.1007/s10459-019-09930-4

14. Dolmans DHJM. How theory and design-based research can mature PBL practice and research. Adv Health Sci Educ. 2019;24 (5):879-891. doi:10.1007/s10459-019-09940-2

15. Chung EY. Facilitating learning of community-based rehabilitation through problem-based learning in higher education. BMC Med Educ. 2019;19(1):1-14. doi:10.1186/s12909-019-1868-4

16. Dolmans DHJM, Loyens SMM, Marcq H, et al. Deep and surface learning in problem-based learning: a review of the literature. $A d v$ Health Sci Educ. 2016;21(5):1087-1112. doi:10.1007/s10459-0159645-6 


\section{Publish your work in this journal}

Advances in Medical Education and Practice is an international, peerreviewed, open access journal that aims to present and publish research on Medical Education covering medical, dental, nursing and allied health care professional education. The journal covers undergraduate education, postgraduate training and continuing medical education including emerging trends and innovative models linking education, research, and health care services. The manuscript management system is completely online and includes a very quick and fair peer-review system. Visit http://www.dovepress.com/testimonials.php to read real quotes from published authors. 